\title{
Cheated: Digital technologies in Islamic art practice
}

\author{
Sara Choudhrey \\ University of Kent \\ School of Engineering \& Digital Arts \\ Canterbury, UK \\ s.choudhrey@kent.ac.uk
}

\begin{abstract}
"The computer doesn't count... that's not a real drawing". This paper presents perceptions and attitudes surrounding the use of digital technologies and its impact on the way contemporary Islamic art may be valued. Expanding on findings from interviews conducted in 2015/16, this paper additionally considers anecdotal evidence and online interactions, drawing on artists' experiences of working with digital technologies. Themes of authenticity, authorship and creativity are presented from the perspective of the artist, discussed with the aim of highlighting how understanding of artistic practice of a digital nature may stem from, and conflate, prevailing notions of how we value art on a wider scale. The author will bring focus to the heightened circumstances of this within the field of Islamic art with examples from the online community. Islamic art is often discussed in relation to traditional and hand-made methods. For some, even the use of handmade tools and media play a role in the spiritual experience of making an artwork (Choudhrey 2018). The choice of tools and methods can also lead to a grappling of the conscience, a desire to maintain one's principles (Berry 2018). For others, it allows for a timeless continuity, and forms a basis for maintaining historical convention. However, within such sentiments there is an opposing implication: the fear of a waning tradition, and a discontinuity from art history. As can be expected, artist responses to the incorporation of digital technology in their practice differ. Whilst many indicate a need to adhere to underlying principles of authenticity - encouraged in relation to an Islamic ethos (Nasr 2012), some liken the use of digital technologies with 'cheating'. The repercussion of such language implies a denigration of evolving art-making processes. Yet, often the same artists also discuss digital technologies as providing solutions, an opportunity for exploration, innovation, and an extension of creative capabilities. By shedding insight into the methods and concepts adopted by artists, this paper encourages a shift in how digital forms of Islamic art are perceived by existing and new audiences.
\end{abstract}

Islamic art. Digital art. Spirituality.

\section{INTRODUCTION}

Between 2015 and 2016 ten artists were selected for interview based on their work having been selfdescribed, academically discussed or previously curated as influenced or inspired by Islamic art and culture. The basis for exploration of this subject was instigated by the author's personal engagement within this field leading to $\mathrm{PhD}$ research considering the use of digital technologies in contemporary Islamic art (Choudhrey 2018).

The use of digital technologies for producing and presenting art is not a new or unique activity, however for artists of Islamic art, questions, validations and disclaimers surrounding such practice continue. The questions raised become more poignant when considering their implications alongside Islamic principles and concepts of spirituality. This theme is now explored further with recent evidence collated through mixed-methods to include personal anecdotes, posts on the Instagram social media platform and through personal communications with artists and practitioners. The array of evidence is used to provide a range of views and provide a better understanding of the subtle and nuanced differences in approaching Islamic artistic practice.

Within the findings from the interviews there was a strong acknowledgement of the benefits in adopting digital and computer technologies, where use of these were said to ease processes, allow use of generative forms, algorithms and enable the ability to repeat, undo and experiment with visual outcomes prior to making a final commitment in the artwork. The various uses the artists favoured for their digital engagement within practice was as 
varied as they were as individuals - of various ethnic backgrounds, and of religious and nonreligious inclinations (Muslim and non-Muslim). Some chose to use digital technologies as tools, others as media.

\section{THE ROLE OF THE ARTIST}

The descriptions provided by artists of their practice demonstrated that authorship was important and that their role as the creative should be clearly understood, clarifying that the computer or digital technology worked as a separate facilitation of the practice, for example using this to present an array of self-generating colours in an animation, or used as a means to produce a mock-up for a mural. Where the artist makes choices regarding colour, textures, medium and structure, or where they may conduct the finishing touches with a final coat of paint or the sanding of a surface, are all details which feed the perception of the artists role in the art-making process. These expressions ensure the role of the creative is understood and differentiated to any part the computer or technology has played in the production of the work. Such explanations were also insightful for providing an impression of how audiences had previously understood (or not understood) the artists' practice. This awareness of the audience's perspective in how artwork is viewed and subsequently valued is demonstrative of the author's own experience through audience interaction.

\section{AUDIENCE PERCEPTIONS}

During an informal conversation with an art historian in 2016 (Anonymous personal communication, 27 Jan 2016), a discussion of contemporary art was pursued leading to introduction to the author's own artistic practice. The methods used in the production of the author's artwork, including laser cutting and engraving was mentioned, to which the response was "but that's just a manufacturing process". A subjective impression had been quickly formed based on this limited detail prior to further elaboration. If the practice had primarily been described with emphasis on the themes and subjects of the work, this may have provided an altered impression. Therefore, the language used to communicate the art-making process can impact how it is perceived by others and even prepare one to defend their choices (Jones 2019).

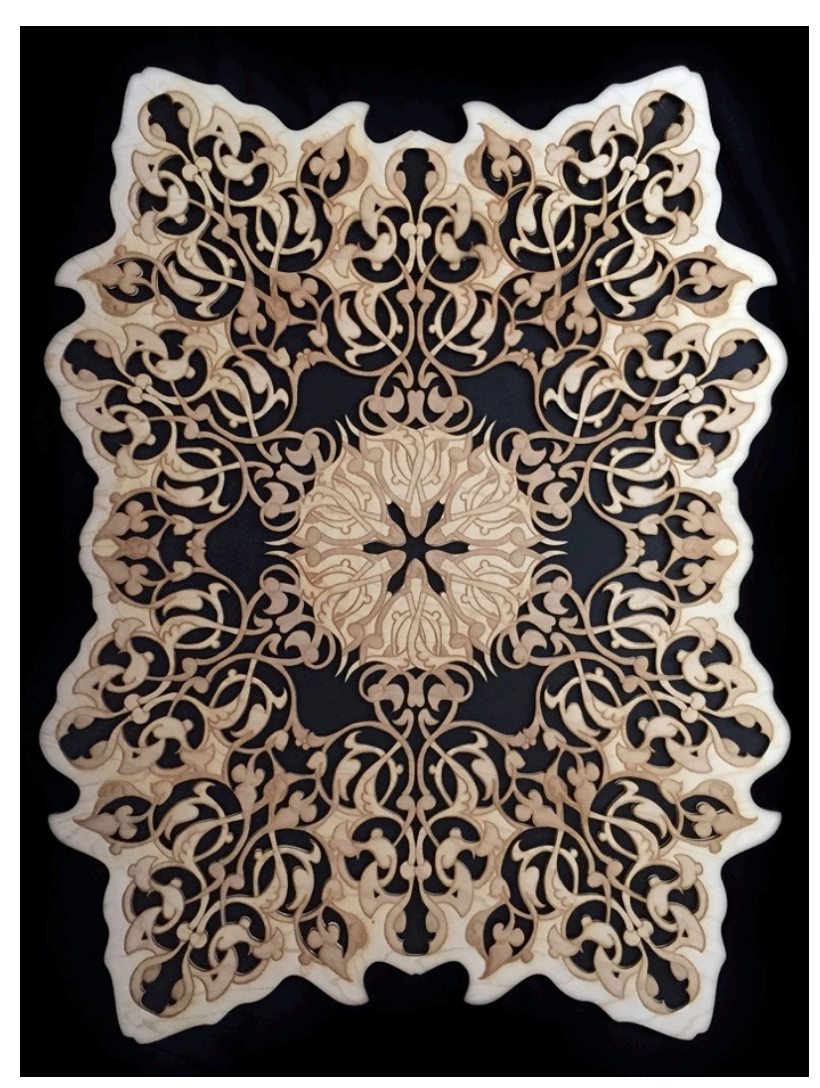

Figure 1: Arabesque II, Sara Choudhrey, 2015

Recalling a further experience later in 2016, the author had curated and exhibited the Seeing the Unseen exhibition in London. A visitor viewing the artwork Arabesque II (see Figure 1), extolled the decorative design of the work and enquired if it had been carved by hand. After describing that laser engraving had been used to apply the design to the wood, the visitor's response was to recollect a past era in which "that would have taken someone hours to make". The author felt inclined to assure them that this piece too, had taken many hours to make.

On a contrasting note, where a non-digital artwork has been mistaken for being digital, a more positive connotation is implied. In the same year, during a display of the author's paintings (see Figure 2) for the Pigments of Life exhibition in Canterbury, the awed response from a visitor was "I thought they were digital". The immediate feeling this evoked was one of pride, that a level of accuracy and neatness might have been achieved in a handdrawn and painted composition that was mistaken for being a computer drawing. 


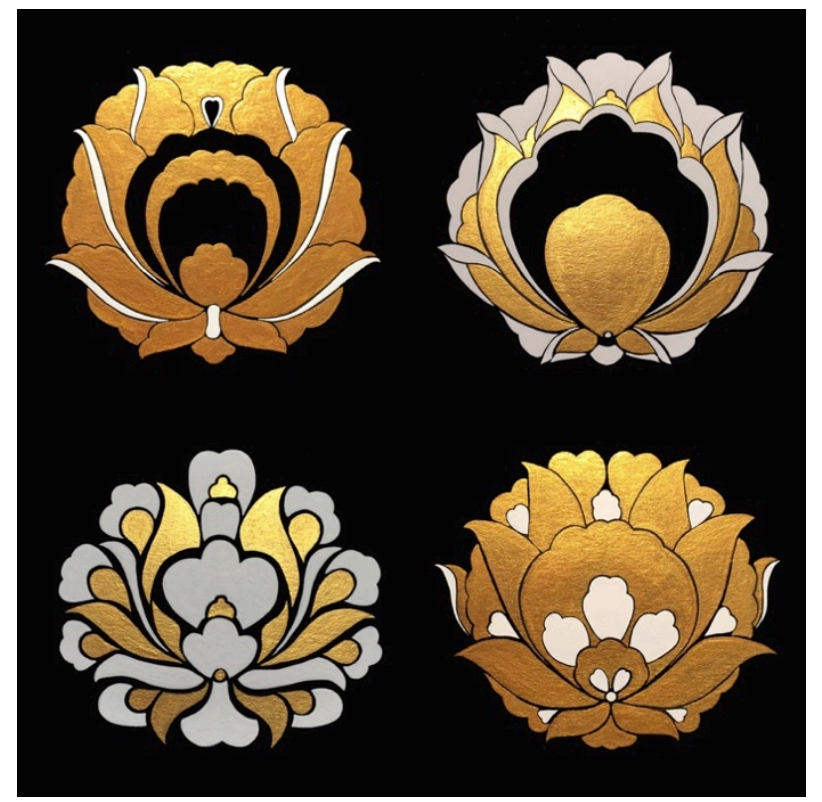

Figure 2: Iznik Gold Series I - IV, Sara Choudhrey, 2016

\section{VALUING PROCESS}

Although computers, software and technologies can supplement, complement and even ease and speed up some processes of making, many artists will spend a length of time in designing, practicing, prototyping and experimenting before completing an artwork. The measure of 'time' appears to be dismissed from preceding activities that lead to the act of making the final artwork, for example the development, the planning, the proto-typing, the sketching, the testing, prior to working on the final piece alone.

These aspects of art-making may be less known to their audiences, yet to ensure it is valued appropriately, the artist is thus compelled to provide further explanation of their practice and indicate the length of time invested in the process. This perspective in valuing art is further influenced by the long-held idiom 'time is money' and forms the foundation upon which artists are encouraged to price their work (Gan 2017). However, time is invested in a number of preceding stages of an artwork's development and completion including a possible period of training, familiarising oneself with tools and learning new techniques.

Having an increasing presence on social media, artists are now able to share their work with larger, more varied and geographically distant audiences whilst enabling interaction with comments. Using a platform such as Instagram has encouraged sharing not just visual content but expression of personal experiences of art-making through the use of captions and hashtags (for example \#wip is commonly used to denote a 'work in progress'). Using this platform as a means to share images of paintings and drawings with followers, artist Siddiqa Juma has openly commented on how some of her digital art has been dismissed in comparison to her canvas paintings. In 2017, Juma shared a number of posts of her digital series, and used the captions to highlight the misconceptions people have around digital art, describing it as "a skill in its own right". On a further post she says: “... they don't think much work is required to create an image digitally. Actually, it can be very time-consuming, if not more time-consuming than painting a canvas" (Juma 2017).

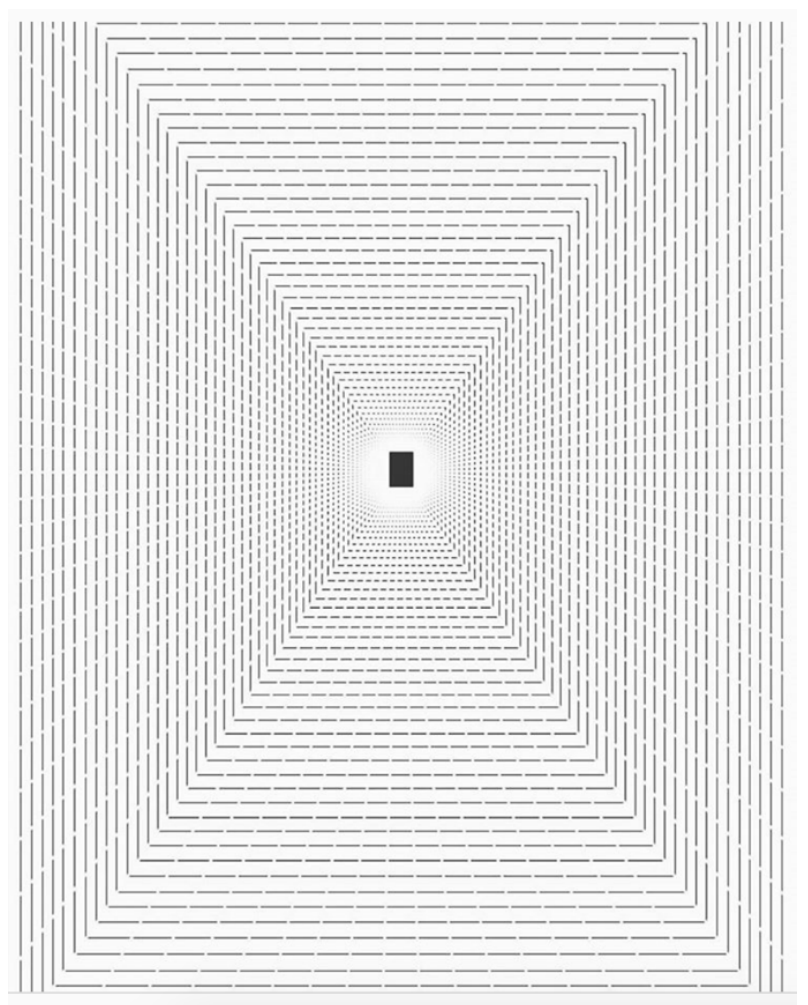

Figure 3: Perspective, Siddiqa Juma, 2017

One of Juma's followers, Rakhshinda Haris commented that she would be interested to see more of Juma's digital art, explaining: "few Muslims are doing digital paintings" (Juma 2017).

Haris is herself an artist, working on Islamic art of the Islimi (floral pattern) form. Looking at the content of her own Instagram account it is interesting to observe that she also has now ventured into digital artistic practice. She was recently requested by a client to produce a bespoke digital artwork. Haris shared a screenshot of this work in progress on Instagram, which shows a view of the Adobe Photoshop software interface she was using (2020). Her caption explained that she had used this software for the first time to create the artwork and felt the process was similar and as manually challenging as if drawing a painting on paper. 


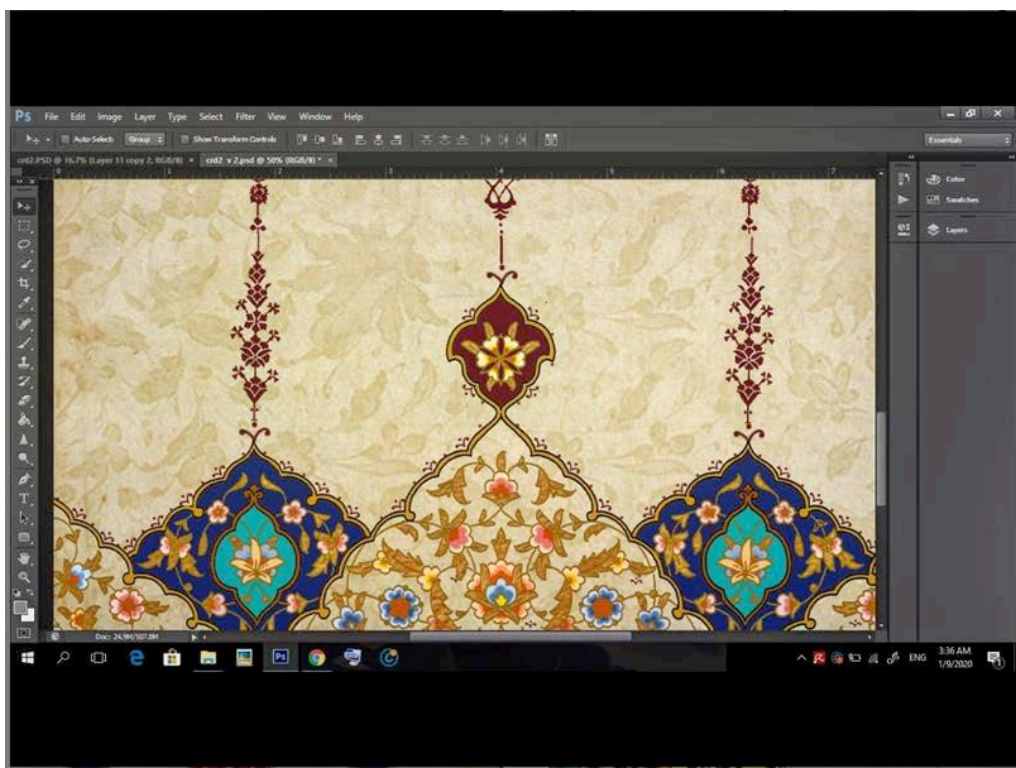

Figure 4: Instagram post by Rakhshinda Haris (@rakshindasart), 2020

Through an exchange of direct messages with the author (Haris, R., personal communication 20 Feb 2020), Haris described in further detail that she had used a Wacom tablet for the drawing of her digital design. She felt the digital drawing was less timeconsuming and although an exciting experience, not an easy task. She still felt that working "manually" (as opposed to digitally) was very close to her heart but feels that "living in a digital world we can't ignore its possibilities to create Islamic art".

Instagram is increasingly used by artists to promote their work, generate interest and even sales (Kang $\&$ Chen 2017). The author often uses the platform to inform followers of news, exhibitions, progress in research or development in practice and new artworks. It has become an invaluable means for staying in touch with large audiences and to feel connected to a community of like-minded interest groups.

Following a number of artists of similar artistic interest, the author was intrigued to see a post by @Toafeek (Taufiq Dawood) posting an image of a papercut arch design made up of an intricate Islamic geometric pattern. Dawood shared in his caption that he had used a Cricut (fabric cutting) machine to produce the piece and was "amazed by the precision" (2019). Although he also appears to consider further possibilities in using the machine, he ends his caption with "still think it's cheating though". This caveat is similar to one expressed by artist Raanaz Shahid in a TV interview for the Living the Life show on Islam Channel (2016), who felt laser cutting would be cheating, preferring to cut her patterns by hand (Choudhrey 2018). toafeek

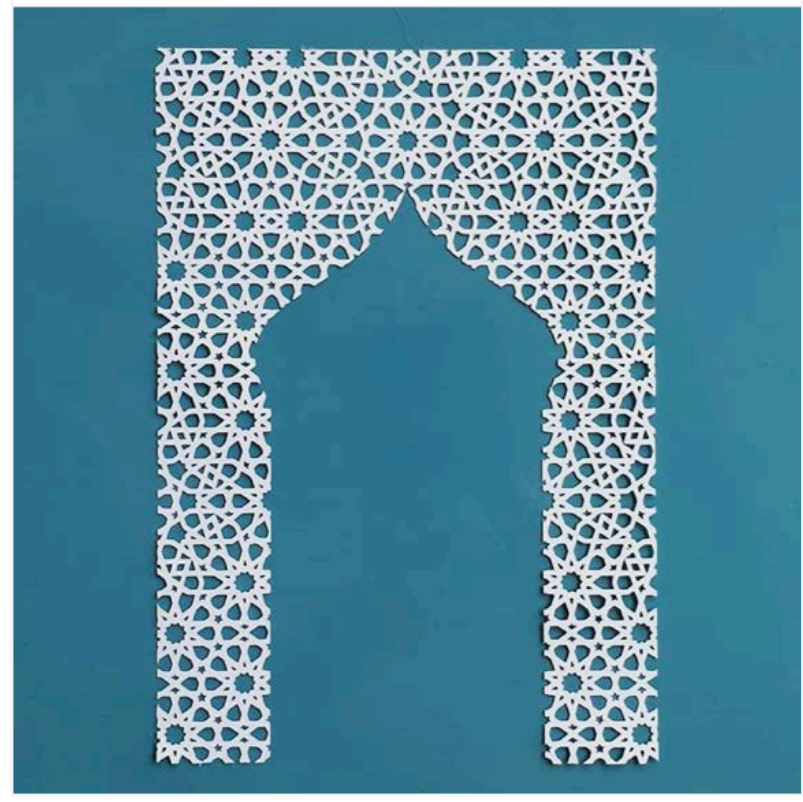

Figure 5: Instagram post by @Toafeek, 2019

Prompted by @Toafeek's caption, Ameet Hindocha (@Ambigraph), also an artist, geometer and teacher, responded by commenting that he does not "think of tools that extend your capabilities as cheating...". In turn @Toafeek responds with a consideration to further experiment with the machine. The opportunity for the platform to result in an exchange of ideas has demonstrated a positive encouragement can be given to see alternative perspectives. 
As discussed above, digital technologies can provide some ease by simplifying and reducing steps within artistic practice, however, by implying this is 'cheating' carries a number of connotations, primarily one of dishonesty, or deception. In the context of art-making, it may be seen as avoidance of a longer or more difficult step in the process of the making. Yet, regardless of the advancing developments in digital, new media and computer art (2019), the use of digital or computing methods in art remains a contested issue (Cozza 2017, Cruz 2020).

The notion of cheating from an Islamic ethical perspective is interpreted as a deliberate intention to deceive, to present some falsehood or convey an untruth (Ibrahim 2015). The amoral connotation is one of shame to someone who might be using an Islamic moral compass to guide their everyday actions. For the Islamic or Muslim artist, such as the author, this would be of high importance, regardless of the subject of their artwork. For many Muslims, the integration of Islamic morals manifests (even unintentionally) in all aspects of one's life, including in artistic practice (Nasr 1987).

The author acknowledges that it is unlikely that the term 'cheating' in the above examples had been used in an accusatory manner, rather it appears to be a reflection of artists' preferences in art-making methods specific to their own practice. Through personal communication, Ameet Hindocha was able to shed further light on why this might be:

\begin{abstract}
I think there can be some 'tool purism' within the world of Islamic geometry. For example, drawing patterns with only ruler and compass encourages a clarity of understanding of the underlying structures that purely digital exploration can overlook. Yet, I find that working both by hand and digitally has led to a very fruitful drawing practice and the different approaches inform each other (Hindocha, personal communication, 16 March 2020).
\end{abstract}

\section{GUIDING PRINCIPLES}

The Islamic art community in the United Kingdom is growing, and has a strong network founded on an appreciation of pattern-making as a process of learning. A number of studios cater to the desire to learn more on the subject.

Whilst visiting the Sussex based studios of Sacred Art of Geometry in 2018, the author met one of the founders Daniel Docherty. After some discussion of the author's research interests, Docherty, asked if the publication 'Why I am not going to buy a computer' had been read (Berry 2018). The title was first published as an article In Harper's Magazine in 1987, and was recently republished as part of the Penguin Modern series (2018) to include a number of letters sent in response to the original article, and Berry's responses back to the readers. It is a provocatively titled article, however in a short piece, Berry expresses his desire to maintain, nurture and sustain as naturally consumable and recyclable a lifestyle as possible. In relation to this he avoids consuming or depending on technologies, including computers, which he is told, would be of benefit to him as an established writer. His readers are quick to cite how their own activities have been eased, sped up and made more efficient by adopting computers. Berry argues that a computer would not add to his creative process nor improve his writing skills, but would just present the writing in another format. Therefore, he is able to manage and enjoy his practice with the satisfaction of doing so whilst in adherence to his principles regarding use of natural materials where possible.

The principles upon which Berry refuses to 'buy a computer' are shared from his perspective as an environmental activist (Skinner 2012). Therefore, although some of Berry's readers may not have agreed with his views regarding the adoption of technology, they would be hard-pressed to disagree with his intentions, which are guided by a commitment to the natural environment and his desire to reduce his impact upon it. Berry's example demonstrates how a creative may deliberately self-limit the tools and media with which they work as a form of adherence to a set of strongly held beliefs.

Art of Islamic Pattern (AOIP), another creative teaching studio, was founded and run by artists Richard Henry and Adam Williamson and celebrated its ten-year anniversary in 2019. They curated an exhibition The Art of Islamic Pattern - A Living Tradition, which included a variety of student work, produced by hand, such as ceramic tiles, wooden parquetry designs, watercolour paintings, and collages. It was a celebration of a decade of teaching pattern making to both local and international students. The exhibition demonstrated the resurgence of interest in Islamic art over the last decade, with an increasing popularity for courses in geometry and biomorphic designs from the Islamic world. The surge in interest has been described as a revival (Art of Islamic Pattern 2020) and caters to artists, designers and first-time enthusiasts. The courses aim to cover the foundations and principles of Islamic patternmaking in order to enable creatives to then apply these principles appropriately to any medium. 


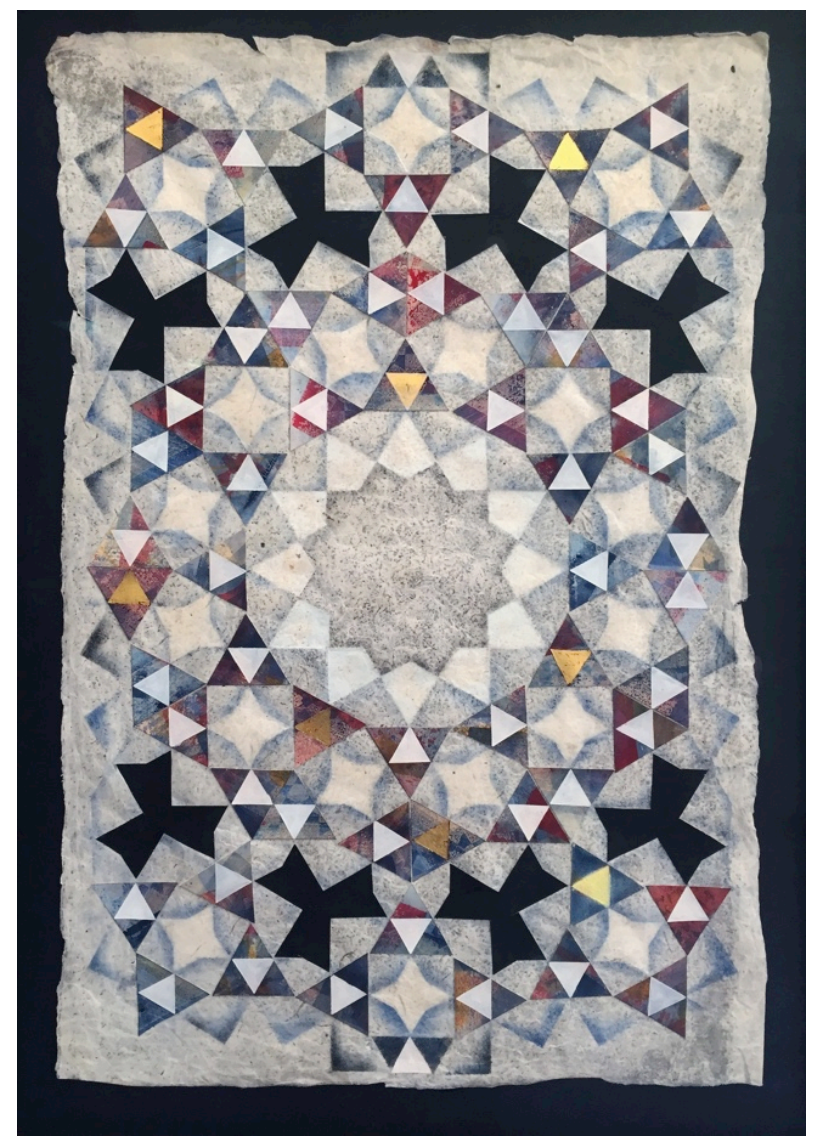

Figure 6: Harlequin, Richard Henry, 2019

Towards the end of 2019, the author joined an advanced geometry course at the AOIP studios. During a demonstration of pattern construction, Henry spoke of his experience of drawing patterns on the computer for the purpose of producing instructional handouts for students. He described this as "not the same" as drawing the pattern using the traditional tools of compass and ruler. Upon completing the demonstrative drafting for the class, he stated that it was the first time he had drawn that particular pattern, and that the previous version on the computer "didn't count". Upon further exploring the topic Henry explained that for the purposes of teaching and production of student handouts the use of a computer has become imperative and something he is dependent on. However, this greatly differs from his own artistic practice where the artwork can take on a different materiality:

You still experience it on the computer, but in a different way. The sense of the drawing as an organic whole, the idea of something made manifest in the world, is what one experiences drawing it by hand (Henry, personal communication, 20 March 2020).

\section{THE HAND AND SPIRITUALITY}

This idea of the involvement of the hand is an interesting one, which continues to be a strong point for art-makers. Phrases such as 'hand-made', 'hand-finished' and the 'human-touch', which were often used by interviewees, conveyed that the artist's role is a physical part of their practice too, making the outcome unique to them. However, through this physical connection, the part of the 'hand' in the making process was also spoken of in relation to a spiritual connectedness.

In June 2017, artist Nazira Bibi shared a post of her work on Instagram, displaying a photo of a geometric pattern carved into slate. The accompanying caption included the phrase "sometimes the hand and heart know what the mind can't acknowledge" (Bibi 2017). Bibi, who is a graduate of the MA from the Princes Foundation School of Traditional Arts, was further able to expand on this concept of a physical and spiritual connectedness with reference to Qur'anic scripture:

A traditionalist would believe that you have some sort of synchronisation between the hand, the head and the heart, the three working in harmony effectively becomes a meditation, a process of reflection. Within the Islamic tradition, Allah (God) in the Qur'an invites you over again: "indeed there are signs for those who reflect (Bibi, N., personal communication, 14 March 2020).

Returning to the work of Siddiqa Juma, we find that although there is no stipulation of how the hand is used, she also describes her work as a meditative process, an extension of her "innermost conversations with God" (Juma 2018). There is no indication made by Juma that the digital works have a different spiritual engagement to the nondigital, and so the assumption can be made that the materiality of the work does not detract from her spiritual connectedness.

From a personal perspective, the author has an experimental approach to exploring making methods, using tools and media, which align with the work as opposed to a desire to utilise a specific technology for its own sake. The spiritual connectedness is not one she explores as a direct result of art-making but one that is present as an adherence to an Islamic outlook and ethos embodied to all aspects of life. This would include presenting an honest, accessible and transparent manner in work, allowing people to connect through the themes addressed in the work and to build conversations around it. 


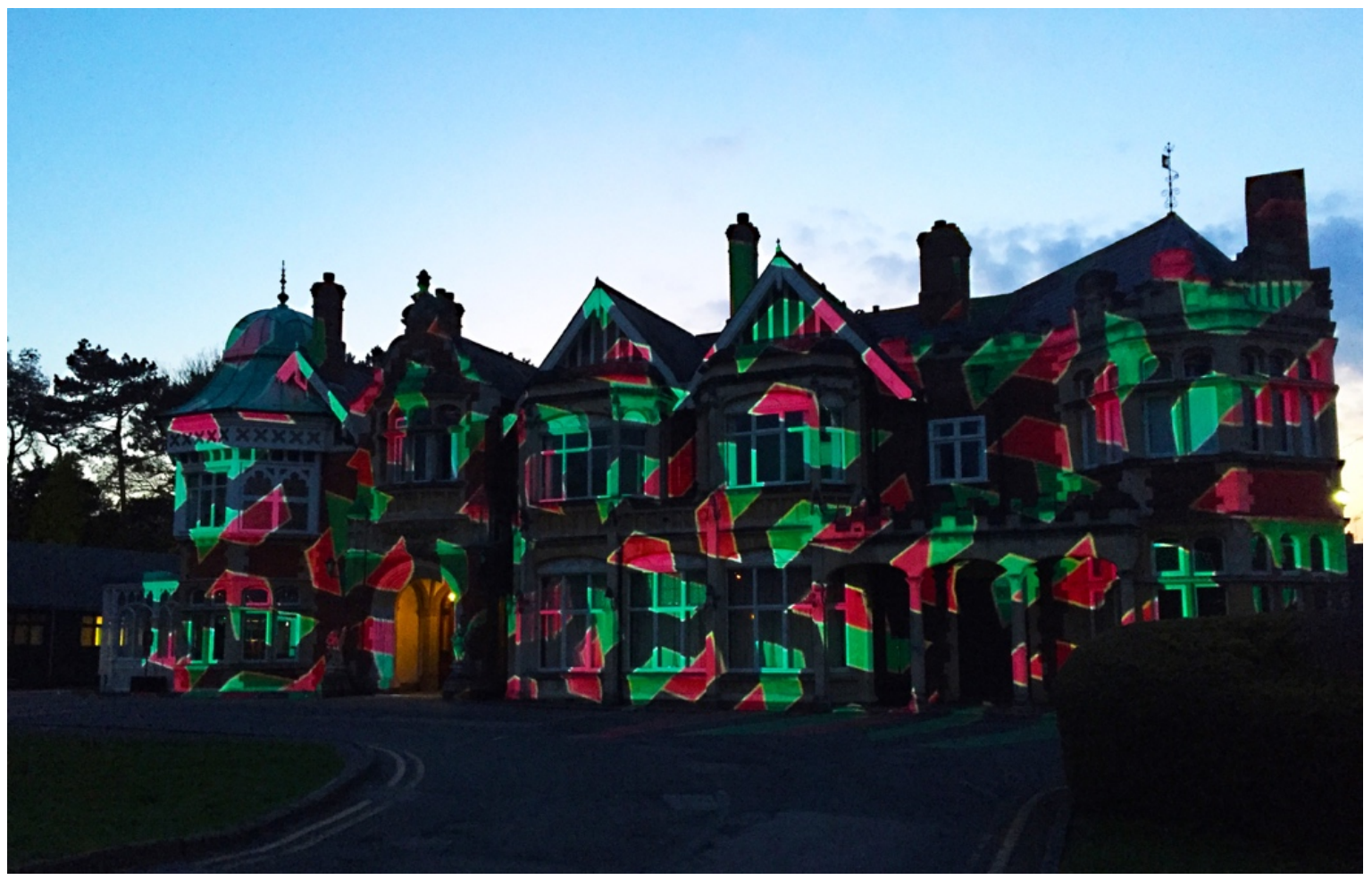

Figure 7: Artwork by Sara Choudhrey presented as part of Digital Light Code Makers at Bletchley Park. Commissioned by MKIAC, animated by MBD Ltd. Image: Karen Kodish, 2020.

Accessibility is one aspect that the author feels is enabled by the use of digital technologies. There are number of artworks which, without computing and digital technologies, would not be possible to present, such as temporary large-scale public displays utilising projection mapping. Between 2019-2020, the author was commissioned by Milton Keynes Islamic Arts, Heritage and Culture to work on an animation to be mapped onto the façade of the iconic mansion at Bletchley Park (Bletchley Park 2020). The artwork Digital Light: Code Makers at Bletchley Park was produced in collaboration with a number of creatives, however presentation of such a large-scale display would not have been possible on a historical heritage site without digital intervention. The use of projections opened up the possibilities to draw in and connect with new audiences to view Islamic art in a new context. The site-specific display was designed to draw on the connections between mathematics, science, patterns, computing and Islamic culture.

\section{CONCLUSION}

The over-arching themes in this paper covered attitudes and values related to how digital art practice is perceived, with specific examples from the context of contemporary Islamic art. The research used a combination of mixed methods, including interviews, Instagram posts, anecdotes and personal communications with a number of artists and practitioners in the Islamic art field.
Based on the examples explored, it appears that inevitable assumptions will be made regarding a practice that an audience may be unfamiliar with. However, if given the opportunity, questions can be raised and directed to the artist or curator with the intent to lead to more meaningful discussions surrounding the themes of the work. The audience's response to one's art can be intriguing, insightful, motivating and immensely helpful for judging the successful execution and impact of an artwork. It can also form the basis upon which to further develop the artwork or the artist's practice (Graham 2017, Fenton 2014).

This paper therefore suggests a re-consideration by makers and audiences of Islamic art who may perceive tradition is only produced and reasserted through specific tools and media, rather than considering that the understanding and application of underlying principles and methodology can be achieved through many variations in practice including the digital.

The use of digital technologies is continually expanding, allowing for evolving ideas of what it means to create, challenging notions of the role of the artist, and providing an abundance of possibilities to engage new audiences and creatives in the process. 


\section{REFERENCES}

Art of Islamic Pattern (2020) Open Studio. https://artofislamicpattern.com/exhibition/ (retrieved 18 March 2020).

Berry, W. (2018) Why I Am Not going to Buy a Computer. Penguin Books, London.

Bibi, N. (2017) "Seek knowledge, even unto China" Moroccan 8-fold meets yin/yang. Slate..., 13 June [Instagram].

https://www.instagram.com/p/BVSfOV3ltAw/

(retrieved 20 March 2020).

Bletchley Park (2020) Digital Light: Code Makers at Bletchley Park. https://bletchleypark.org.uk/whatson/digital-light-code-makers-at-bletchley-park (retrieved 10 March 2020)

Choudhrey, S. (2018) Pigment to Pixel-An Investigation into Digital Islamic Art in the UK (Doctoral dissertation, University of Kent).

Cozza, A, (2017) Digital Art is Not Cheating. https://www.the9mmberetta.com/digital-art-notcheating/ (retrieved 20 Feb 2020).

Cruz, G. (2020) Is Digital Art Cheating? Kind of, here's why. A Digital Artist's Take. https://blogbygaius.com/is-digital-art-cheating-kindof-heres-why-a-digital-artists-take/ (retrieved 20 Feb 2020).

Fenton, S (2014) The Value of Audience Feedback. http://www.intrinsicimpact.org/the-value-ofaudience-feedback/ (retrieved 20 March 2020).

Gan, H (2017) The Artist's Relationship with Time and Money, Part l: Time. https://medium.com/@HilaryGan/an-artistsrelationship-with-time-and-money-7c2b389ddc8a (retrieved 20 March 2020).

Graham, B. (2014) New Collecting: Exhibiting and Audiences after New Media Art. Ashgate, Farnham.

Haris, R. (2020) Digital Islamic Illumination. 8 Jan [Instagram].

https://www.instagram.com/p/B7E5k2vAXUT/ (retrieved 20 March 2020).

Ibrahim, G. S. A. (2015) Virtues in Muslim Culture: An Interpretation from Islamic Literature, Art and Architecture. New Generation Publishing, London.
Jones, C. (2019) What Artists Talk About When They Talk About Their Art and Why it's Hard to Say Anything Truly Meaningful.

https://medium.com/@chrisjones 32882/whatartists-talk-about-when-they-talk-about-their-art14373a87b452 (retrieved 20 March 2020).

Juma, S. (2017) An abstract digital Kaabah piece of mine. Focus on the centre and you'll notice the natural gravitation of the surroundings, 2 August [Instagram].

https://www.instagram.com/p/BREFKIcgX7e/ (retrieved 20 February 2020).

Juma, S. (2018). The first ever Siddiqa Juma sale on Original paintings.

https://siddiqajuma.co.uk/blogs/news/a-one-timeonly-sale (retrieved 20 March 2020).

Kang, X. and Chen, W. (2017) The Like Economy: The Impact of Interaction between Artists and Fans on Social Media in Art Market. In Proceedings of the International Conference on Business and Information Management (ICBIM 2017). Association for Computing Machinery, New York, NY, USA, 45-49. DOI: https://doi.org/10.1145/3134271.3134281

Nasr, S. H. (1987) Islamic Art and Spirituality. State University of New York Press, New York.

Nasr, S. H. (2012) Islamic Pedagogy: An interview. Islamic Sciences, 10(1), p.7.

Ornes, S. (2019) Science and Culture: Computers take art in new directions, challenging the meaning of creativity. Proceedings of the National Academy of Sciences. doi: 10.1073/pnas.1900883116

Skinner, D. (2012) Wendell E. Berry - Jefferson Lecture.

https://www.neh.gov/about/awards/jeffersonlecture/wendell-e-berry-biography (retrieved 20 March 2020).

Toafeeq (2019) So my wife recently got a cricut machine, and I wanted to see what it could do so I thought, 16 August.

https://www.instagram.com/p/B1O3EjVgH9ul (retrieved 12 Jan 2020). 